\title{
Simonsiellaceae fam.nov. with Characterization of Simonsiella crassa and Alysiella filiformis
}

\author{
By PAMELA D. M. STEED \\ Department of Microbiology, University of Queensland, \\ Brisbane, Australia
}

(Received 18 April 1962)

\begin{abstract}
SUMMARY
The cultural, biochemical and morphological characteristics of six cultures of Simonsiella and four cultures of Alysiella are described. The multicellular filaments of both Simonsiella and Alysiella, originally termed 'disk-bacteria', are ribbon-like, non-sporing, non-branching, aerobic and Gram-negative. They are greater than $2 \mu$ wide, exhibit gliding motility on solid media and ferment carbohydrates. The family Simonsiellaceae fam.nov. is proposed to include the genus Simonsiella Schmid and the genus Alysiella Langeron. Amended descriptions of the species Simonsiella crassa Schmid and of Alysiella filiformis (Schmid) Langeron are given.
\end{abstract}

\section{INTRODUCTION}

In 1906 Müller discovered the 'Scheibenbakterien' or 'disk-bacteria' in tooth sediment and saliva of man and in throat mucus of a chicken (Simons, 1922); Müller (1911) was not sure of their classification as bacteria. Simons (1922) rediscovered these micro-organisms and also examined one of Müller's original preparations whereupon he recognized them as members of the Cyanophyceae. Most of the later workers agreed with Simons who regarded them as Oscillatoria-like forms which had become colourless by adaptation to parasitic or saprophytic conditions. Simons described three species that were classified in the genus Simonsiella by Schmid (Simons, 1922). The type species, $S$. muelleri, occurred in the oral cavity of man and various domestic animals; $S$. crassa, found in the same habitat, was distinguished by its greater width; S. filiformis was present in the mouth mucus of domestic animals but, because it differed morphologically, Simons questioned its inclusion in the genus Simonsiella. He regarded them all as harmless saprophytes. Langeron (1923) excluded $S$. filiformis from the genus Simonsiella and placed it in the new genus Alysiella. To illustrate the basis of generic differentiation Langeron defined both genera. The following is a free translation:

Genus Simonsiella: Colourless, non-motile trichomes formed of short elements; from 7-20 $\mu$ long and 2-3 $\mu$ wide without cap-cells or apical thickenings but with a mucilagenous envelope; divided by numerous transverse septa into narrow compartments whose width does not exceed $0 \cdot 4-0 \cdot 7 \mu$; numerous hormogonia 3-5 $\mu$ long arising from constriction of the trichomes; cytoplasm very basophilic, rarely granular; spores unknown.

Genus Alysiella: Colourless, non-motile trichomes of variable and indefinite length; flat, striped, segmented into articulated units like segments of a tapeworm; 
units are all alike; no mucilagenous envelope; very small hormogonia formed from one or more units generally paired; cytoplasm basophilic, often granular; spores unknown.

\section{METHODS}

Unless stated otherwise cultures were incubated aerobically at $37^{\circ}$. Liquid media were dispensed in $5 \mathrm{ml}$. quantities in $150 \times 13 \mathrm{~mm}$. test tubes. When first isolated the cultures required $10 \%$ serum (horse or ox) added to Oxoid nutrient agar. Therefore $10 \%$ serum was included in the various test media except those used for nutritional studies. Selected cultures known to give positive reactions and uninoculated controls, all containing serum, were included.

Source and isolation of cultures. Borax methylene blue-stained smears of rabbit and sheep saliva revealed the organisms by their characteristic morphology. Oral swabs were plated out on $10 \%$ serum agar and incubated at $37^{\circ}$ for about $6 \mathrm{hr}$., by which time microcolonies, mainly over deposited epithelial cells, were visible by phase-contrast microscopy. These were transferred to new media with a microinstrument designed by Professor V. B. D. Skerman (to be published).

Several pure cultures were obtained from rabbits and from sheep. Those from rabbits were difficult to maintain and are being reserved for subsequent research. Ten cultures (A1 to A4 and S1 to S6) from sheep were used for this study. These represented two distinct morphological forms.

Preservation of cultures. Cultures were grown at $37^{\circ}$ in $10 \%$ horse serum in

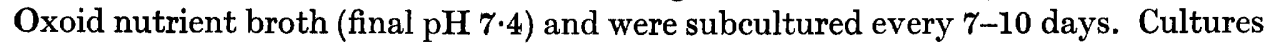
were freeze-dried by using 1-2 day serum agar slope cultures washed with culturedrying fluid. This fluid was prepared by mixing 3 volumes of sterile serum with 1 volume of a Seitz-filtered solution containing $12 \%$ peptone and $30 \%$ glucose.

\section{Staining and morphology}

Heat-fixed smears prepared from 6 -hr. cultures on serum agar were stained by the Gram procedure, by $0 \cdot 1 \%$ basic fuchsin (1 min.) and by $3 \%$ acid fuchsin ( $1 \mathrm{~min}$.). Representative cultures $\mathbf{S} 6$ and $\mathbf{A} 1$ were stained for flagella by the method of Leifson (1951, 1958).

General morphology and motility were observed by phase-contrast studies of microcolonies on agar plates and slide cultures. A clean sterile glass slide placed on a flat agar base in a Petri dish was covered with a thin layer of serum agar. When set the serum agar was inoculated with several drops of a young serum broth culture distributed uniformly over the slide area. After incubation for about $6 \mathrm{hr}$. the slide was cut out. Examination was made by using the low power phase-contrast objective for evidence of slime trails before applying a coverglass and observing with the oil immersion phase-contrast objective for morphology and any evidence of cell movement. Cultures were also examined for motility in liquid medium by a hanging drop procedure (Skerman, 1959).

Photomicrographs were taken on Adox KB 14 film with a Leica $35 \mathrm{~mm}$. camera attached to a Reichert phase-contrast RC microscope. 


\section{Metabolism and nutrition}

Anaerobic growth. Serum agar plate cultures were incubated anaerobically for 4. days by using the pyrogallol plate method (Skerman, 1959) and the McIntosh \& Fildes jar.

Growth temperature. Serum broth cultures were incubated in water baths at temperatures of $20^{\circ}, 37^{\circ}, 45^{\circ}$ and $60^{\circ}$ for $24 \mathrm{hr}$.

$\mathrm{pH}$ Value for growth. Serum broths adjusted to $\mathrm{pH}$ values of 4, 5, 6, 7, 8, 9 and 10 were inoculated and examined for growth after incubation for 7 days. Phenol red indicator was included in the medium to detect local $\mathrm{pH}$ reaction in control tubes during incubation.

Utilization of citrate as the sole source of carbon. The Oxoid product of Simmons citrate agar medium (Oxoid Manual, 1961, 2nd ed.) was inoculated and incubated for 4 days.

Growth requirements. Plates of serum agar, Oxoid nutrient agar, and peptone yeast extract (PYE) agar were inoculated and incubated for 2 days, then examined for growth. PYE agar was prepared by dissolving $1 \%(\mathrm{w} / \mathrm{v})$ Bactopeptone (Difco), $0.5 \%(\mathrm{w} / \mathrm{v}$ ) Bacto yeast extract (Difco), $0.5 \%(\mathrm{w} / \mathrm{v}) \mathrm{NaCl}$, and $1.4 \%(\mathrm{w} / \mathrm{v})$ Bacto agar (Difco) in distilled water, adjusting to $\mathrm{pH} 7 \cdot 2$ and then autoclaving at $121^{\circ}$ for $20 \mathrm{~min}$.

\section{Fermentation of carbohydrates}

Preliminary tests with $5 \mathrm{ml}$. of carbohydrate serum water in a $150 \times 13 \mathrm{~mm}$. tube did not show any acid production from glucose. The test was positive, however, in a liquid medium prepared by adding $1 \%$ carbohydrate and $0.1 \%$ phenol red to serum broth dispensed in $0.5 \mathrm{ml}$. quantities in $75 \times 13 \mathrm{~mm}$. flat-bottomed test tubes. A moist atmosphere during incubation was required to prevent evaporation. Similar reactions were obtained with a solid medium consisting of $1 \%$ carbohydrate and $0.1 \%$ phenol red in serum agar poured as a layer over a nutrient agar base. Both media were inoculated with drops of serum broth cultures.

\section{Biochemical tests}

Hydrolysis of aesculin. The medium described by Sneath (1956) was modified by adding $10 \%$ serum and altering to $\mathrm{pH} 7 \cdot 4$. After incubation for 4 days the plates were examined for presence of the brown colour indicating aesculin hydrolysis.

Hydrolysis of casein. Oxoid nutrient agar containing $20 \%$ skim milk was poured in $5 \mathrm{ml}$. quantities over a saline agar base. Plates were incubated for 2 days.

Litmus milk. The medium was prepared as described by Skerman (1959) with spray-dried powdered milk; incubation period 7 days.

Indole production. Serum broth $+1 \%$ tryptone was incubated for 3 days then tested for indole by adding Ehrlich-Böhme reagent.

Methyl red (M.R.) and Voges-Proskauer (v.P.) tests. Serum (10\%) was added to the glucose phosphate peptone water medium (Kauffmann, 1954) and dispensed in $4 \mathrm{ml}$. quantities. The tests were performed after incubation for 4 days by the methods recommended by Skerman (1959); O'Meara's modification of the v.P. test was used.

Production of $\mathrm{H}_{2} \mathrm{~S}$. Serum broth containing $0.01 \%$ cystine and $0.05 \%$ sodium 
sulphate was used. Production of $\mathrm{H}_{2} \mathrm{~S}$ was detected by the lead acetate paper method recommended by Skerman (1959); incubation period 7 days.

Liquefaction of Loeffler's inspissated serum. Sterile horse serum was added to the sterile glucose peptone water as recommended by Skerman (1959) and $15 \mathrm{ml}$. quantities inspissated at $80^{\circ}$ for $30 \mathrm{~min}$. in Petri dishes. Plates were incubated for 4 days.

Haemolysis. Oxoid nutrient agar containing $10 \%$ citrated horse blood was inoculated by the pour-plate method. Plates were examined after incubation for $18 \mathrm{hr}$.

Methylene blue reduction. One drop of $1 \%$ aqueous methylene blue was added to each $24 \mathrm{hr}$. serum broth culture. The result was observed after re-incubation for $30 \mathrm{~min}$.

Reduction of nitrate to nitrite. Peptone water and serum broth media containing $0.2 \% \mathrm{KNO}_{3}$ were inoculated and tested according to the procedure of Skerman (1959).

Catalase. The test described by Sneath (1956) was performed on 1-2 day serum agar cultures.

Urease. The medium recommended by Skerman (1959) was modified by adding $10 \%$ serum and including only $1 \%$ urea, since $2 \%$ urea in serum agar inhibited growth of the cultures. The incubation period was $\mathbf{7}$ days.

Hydrolysis of gelatin. The medium recommended by Skerman (1959) was prepared with Oxoid nutrient agar as the base. Plates were incubated for 4 days then tested with acid mercuric chloride.

Hydrolysis of starch. PYE agar was the basal medium used to prepare starch agar described by Skerman (1959). After incubation for 4 days hydrolysis was tested for by flooding the plates with $96 \%(v / v)$ ethanol in water and examining for zones of clearing.

Glucose utilization. Hugh \& Leifson's medium (1953) containing $1 \%$ glucose as carbohydrate was modified by adding $10 \%$ serum. Incubation period was 2 weeks. A second method, described by Lysenko (1961), was also tested. This medium was modified by adding $10 \%$ serum and adjusting to $\mathrm{pH} 7 \cdot 4$, then dispensed in $0.5 \mathrm{ml}$. quantities in $75 \times 13 \mathrm{~mm}$. flat-bottomed test tubes. The reaction was observed after incubation for 1 week in a moist atmosphere.

Hippurate hydrolysis. The test was performed as described by Ayers \& Rupp (1922) but was modified by adding $10 \%$ serum to the medium.

\section{RESULTS}

\section{Staining reactions and morphology}

All cultures stained Gram-negative and were basophilic. There was no evidence of flagella. Examination by phase-contrast microscopy presented the following morphological features.

Strains S1 to S6. These organisms (see Pl. 1, figs. 1-4) were multicellular filaments consisting of a series of closely apposed cells, about $0 \cdot 6 \mu$ long and 3-4 $\mu$ wide, with the terminal cells hemispherical (compare Oscillatoria). They appeared to divide by constriction into hormogonia-like units that occasionally remained attached for some time. Each unit was 4.5 $\mu$ long. Multi-unit filaments 54 $\mu$ or longer have been observed. 


\section{Characterization of Simonsiella and Alysiella}

Unlike Oscillatoria the multicellular unit was flat, not cylindrical, and measured 1-1.5 $\mu$ in thickness. The organisms frequently turned on their edges and curled up (Pl. 1, fig. 2). Phase-dense areas occurred centrally in the intercalary cells and as apical thickenings in the terminal cells (Pl. 1, figs. 1, 4).

The filaments exhibited active gliding motility in young cultures when the broad base was presented to the solid medium. They showed no translational movement whilst on their edges. Pl. 1, fig. 3, shows organisms at the beginning of migration from a microcolony. Pl. 1, fig. 4, shows the positions of organisms at intervals of $10 \mathrm{~min}$. Slime trails were visible by low power phase-contrast examination of unmounted colonies.

Table 1. Fermentation of carbohydrates by Simonsiella and Alysiella strains

\begin{tabular}{|c|c|c|c|c|c|c|c|c|c|}
\hline \multicolumn{10}{|c|}{ Cultures } \\
\hline S 1 & S2 & S3 & S4 & S5 & S6 & A 1 & A2 & A3 & A4 \\
\hline \multicolumn{10}{|c|}{ Reactions } \\
\hline
\end{tabular}

\begin{tabular}{lllllllllll} 
Carbohydrate & \multicolumn{1}{c}{} & \multicolumn{10}{c}{ Reactions } & & & & \\
Arabinose & $\mathbf{A}$ & $\mathbf{A}$ & $\mathbf{A}$ & $\mathbf{A}$ & $\mathbf{K} / \mathbf{A}$ & $\mathbf{K} / \mathbf{A}$ & $\mathbf{K}$ & $\mathbf{K}$ & $\mathbf{K}$ & $\mathbf{K}$ \\
Rhamnose & $\mathbf{K}$ & $\mathbf{K}$ & $\mathbf{K}$ & $\mathbf{K}$ & $\mathbf{K}$ & $\mathbf{K}$ & $\mathbf{K}$ & $\mathbf{K}$ & $\mathbf{K}$ & $\mathbf{K}$ \\
Ribose & $\mathbf{A}$ & $\mathbf{A}$ & $\mathbf{A}$ & $\mathbf{A}$ & $\mathbf{A}$ & $\mathbf{A}$ & $\mathbf{K}$ & $\mathbf{S A}$ & $\mathbf{K}$ & $\mathbf{K}$ \\
Sorbose & $\mathbf{K}$ & $\mathbf{K}$ & $\mathbf{K}$ & $\mathbf{K}$ & $\mathbf{K}$ & $\mathbf{K}$ & $\mathbf{K}$ & $\mathbf{K}$ & $\mathbf{K}$ & $\mathbf{K}$ \\
Xylose & $\mathbf{K}$ & $\mathbf{K}$ & $\mathbf{K}$ & $\mathbf{K}$ & $\mathbf{K}$ & $\mathbf{K}$ & $\mathbf{K}$ & $\mathbf{K}$ & $\mathbf{K}$ & $\mathbf{K}$ \\
Glucose & $\mathbf{A}$ & $\mathbf{A}$ & $\mathbf{A}$ & $\mathbf{A}$ & $\mathbf{A}$ & $\mathbf{A}$ & $\mathbf{A}$ & $\mathbf{A}$ & $\mathbf{A}$ & $\mathbf{A}$ \\
Fructose & $\mathbf{A}$ & $\mathbf{A}$ & $\mathbf{A}$ & $\mathbf{A}$ & $\mathbf{A}$ & $\mathbf{A}$ & $\mathbf{A}$ & $\mathbf{A}$ & $\mathbf{A}$ & $\mathbf{A}$ \\
Galactose & $\mathbf{K}$ & $\mathbf{K}$ & $\mathbf{K}$ & $\mathbf{K}$ & $\mathbf{K}$ & $\mathbf{K}$ & $\mathbf{K}$ & $\mathbf{K}$ & $\mathbf{K}$ & $\mathbf{K}$ \\
Mannose & $\mathbf{K}$ & $\mathbf{K}$ & $\mathbf{K}$ & $\mathbf{K}$ & $\mathbf{K}$ & $\mathbf{K}$ & $\mathbf{K}$ & $\mathbf{K}$ & $\mathbf{K}$ & $\mathbf{K}$ \\
Lactose & $\mathbf{K}$ & $\mathbf{K}$ & $\mathbf{K}$ & $\mathbf{K}$ & $\mathbf{K}$ & $\mathbf{K}$ & $\mathbf{K}$ & $\mathbf{K}$ & $\mathbf{K}$ & $\mathbf{K}$ \\
Sucrose & $\mathbf{A}$ & $\mathbf{A}$ & $\mathbf{A}$ & $\mathbf{A}$ & $\mathbf{A}$ & $\mathbf{A}$ & $\mathbf{A}$ & $\mathbf{A}$ & $\mathbf{A}$ & $\mathbf{A}$ \\
Maltose & $\mathbf{A}$ & $\mathbf{A}$ & $\mathbf{A}$ & $\mathbf{A}$ & $\mathbf{A}$ & $\mathbf{A}$ & $\mathbf{A}$ & $\mathbf{A}$ & $\mathbf{A}$ & $\mathbf{A}$ \\
Trehalose & $\mathbf{A}$ & $\mathbf{A}$ & $\mathbf{A}$ & $\mathbf{A}$ & $\mathbf{A}$ & $\mathbf{A}$ & $\mathbf{A}$ & $\mathbf{A}$ & $\mathbf{A}$ & $\mathbf{A}$ \\
Melibiose & $\mathbf{K}$ & $\mathbf{K}$ & $\mathbf{K}$ & $\mathbf{K}$ & $\mathbf{K}$ & $\mathbf{K}$ & $\mathbf{K}$ & $\mathbf{K}$ & $\mathbf{K}$ & $\mathbf{K}$ \\
Cellobiose & $\mathbf{K}$ & $\mathbf{K}$ & $\mathbf{K}$ & $\mathbf{K}$ & $\mathbf{K}$ & $\mathbf{K}$ & $\mathbf{K}$ & $\mathbf{K}$ & $\mathbf{K}$ & $\mathbf{K}$ \\
Raffinose & $\mathbf{K}$ & $\mathbf{K}$ & $\mathbf{K}$ & $\mathbf{K}$ & $\mathbf{K}$ & $\mathbf{K}$ & $\mathbf{K}$ & $\mathbf{K}$ & $\mathbf{K}$ & $\mathbf{K}$ \\
Melezitose & $\mathbf{K}$ & $\mathbf{K}$ & $\mathbf{K}$ & $\mathbf{K}$ & $\mathbf{K}$ & $\mathbf{K}$ & $\mathbf{K}$ & $\mathbf{K}$ & $\mathbf{K}$ & $\mathbf{K}$ \\
Inulin & $\mathbf{A}$ & $\mathbf{A}$ & $\mathbf{A}$ & $\mathbf{A}$ & $\mathbf{A}$ & $\mathbf{A}$ & $\mathbf{K}$ & $\mathbf{S A}$ & $\mathbf{K}$ & $\mathbf{K}$ \\
Glycerol & $\mathbf{K}$ & $\mathbf{K}$ & $\mathbf{K}$ & $\mathbf{K}$ & $\mathbf{K}$ & $\mathbf{K}$ & $\mathbf{K}$ & $\mathbf{K}$ & $\mathbf{K}$ & $\mathbf{K}$ \\
Erythritol & $\mathbf{K}$ & $\mathbf{K}$ & $\mathbf{K}$ & $\mathbf{K}$ & $\mathbf{K}$ & $\mathbf{K}$ & $\mathbf{K}$ & $\mathbf{K}$ & $\mathbf{K}$ & $\mathbf{K}$ \\
Mannitol & $\mathbf{A}$ & $\mathbf{A}$ & $\mathbf{A}$ & $\mathbf{A}$ & $\mathbf{K}$ & $\mathbf{K} / \mathbf{A}$ & $\mathbf{K}$ & $\mathbf{K}$ & $\mathbf{K}$ & $\mathbf{K}$ \\
Sorbitol & $\mathbf{K}$ & $\mathbf{K}$ & $\mathbf{K}$ & $\mathbf{K}$ & $\mathbf{K}$ & $\mathbf{K}$ & $\mathbf{K}$ & $\mathbf{K}$ & $\mathbf{K}$ & $\mathbf{K}$ \\
Dulcitol & $\mathbf{K}$ & $\mathbf{K}$ & $\mathbf{K}$ & $\mathbf{K}$ & $\mathbf{K}$ & $\mathbf{K}$ & $\mathbf{K}$ & $\mathbf{K}$ & $\mathbf{K}$ & $\mathbf{K}$ \\
Inositol & $\mathbf{K}$ & $\mathbf{K}$ & $\mathbf{K}$ & $\mathbf{K}$ & $\mathbf{K}$ & $\mathbf{K}$ & $\mathbf{K}$ & $\mathbf{K}$ & $\mathbf{K}$ & $\mathbf{K}$ \\
Salicin & $\mathbf{K}$ & $\mathbf{K}$ & $\mathbf{K}$ & $\mathbf{K}$ & $\mathbf{K}$ & $\mathbf{K}$ & $\mathbf{K}$ & $\mathbf{K}$ & $\mathbf{K}$ & $\mathbf{K}$
\end{tabular}

A, acid; SA, slight acid; $\mathbf{K}$, alkaline to phenol red; $\mathbf{K} / \mathbf{A}$, inconsistent, i.e. sometimes acid, sometimes alkaline.

Strains A1 to A4. This morphological type is illustrated in Pl. 1, figs. 5, 6. They consisted of multicellular filaments whose cells appeared to occur in pairs with a relatively weak linkage between each pair or group of 4 cells. The filaments were of uniform width throughout and the terminal cells were similar to every other cell of the filament in being flat or slightly biconcave. Each cell was 2-3 $\mu$ wide and about $0 \cdot 6 \mu$ long. Like the preceding strains (S1 to $\mathrm{S} 6$ ) the filaments of strains $\mathrm{A} 1$ to A4 were flat, each cell being $0.5 \mu$ thick. Phase-dense areas were sometimes present in the cells as swellings and usually occurred along one side of the filament 
(Pl. 1, figs. 5a,6a). Length of the filaments was variable. Gliding motility was observed in young cultures as a result of which a portion of the filament was often presented in its flattened lateral aspect $(\mathrm{Pl}$. 1, figs. $5 b, 6 b)$. Low power-phase contrast examination of agar plate cultures often revealed numerous slime trails forming a network around the colony.

\section{Cultural characteristics}

None of the strains produced pigment or odour. At $24 \mathrm{hr}$. a ring of turbid growth occurred about $25 \mathrm{~mm}$. below the surface of each serum broth culture, while granular and slightly turbid growth appeared in the top $36 \mathrm{~mm}$. layer of liquid cultures. Pellicle formation was rare. As incubation continued the granular growth was deposited down the side and at the base of the tube until finally only sediment remained, leaving the upper liquid clear. Dispersion of the sediment produced moderate turbidity, although the granular nature often persisted, particularly in cultures A1 to A4.

Table 2. Results of other biochemical tests with strains of Simonsiella and Alysiella

\begin{tabular}{|c|c|c|c|c|c|c|c|c|c|c|}
\hline & \multicolumn{10}{|c|}{ Cultures } \\
\hline & S1 & S2 & S3 & S4 & S5 & S6 & Al & A2 & A3 & A4 \\
\hline Aesculin hydrolysis & - & - & - & - & - & - & - & - & - & - \\
\hline Casein hydrolysis & + & + & + & + & + & + & - & - & - & - \\
\hline Litmus milk & $\mathbf{P}$ & $\mathbf{P}$ & $\mathbf{P}$ & $\mathbf{P}$ & $\mathbf{P}$ & $\mathbf{P}$ & $\mathbf{N}$ & $\mathbf{N}$ & $\mathbf{N}$ & $\mathbf{N}$ \\
\hline Indole & - & - & - & - & - & - & - & - & - & - \\
\hline Methyl-red & - & - & - & - & - & - & - & - & - & - \\
\hline Voges-Proskauer & - & - & - & - & - & - & - & - & - & - \\
\hline $\mathrm{H}_{2} \mathrm{~S}$ production & + & + & + & + & + & + & + & - & + & + \\
\hline Serum liquefaction & + & + & + & + & + & + & - & - & - & - \\
\hline Haemolysis & $\beta$ & $\beta$ & $\beta$ & $\beta$ & $\beta$ & $\beta$ & $\beta$ & $\beta$ & $\beta$ & $\beta$ \\
\hline Methylene blue reduction & - & - & - & - & - & - & - & - & - & - \\
\hline $\mathrm{NO}_{3} \rightarrow \mathrm{NO}_{2}$ & - & - & - & - & + & + & - & - & - & - \\
\hline Catalase & + & + & + & + & + & + & + & + & + & + \\
\hline Urease & - & - & - & - & - & - & - & - & - & - \\
\hline Gelatin hydrolysis & + & + & + & + & + & + & $\mathbf{x}$ & - & + & $\mathbf{x}$ \\
\hline Starch hydrolysis & - & - & - & - & - & - & - & - & - & - \\
\hline Glucose utilization* & $\mathbf{F}$ & $\mathbf{F}$ & $\mathbf{F}$ & $\mathbf{F}$ & $\mathbf{F}$ & $\mathbf{F}$ & $\mathbf{F}$ & F & $\mathbf{F}$ & F \\
\hline Hippurate hydrolysis & - & - & - & - & - & - & - & - & - & - \\
\hline
\end{tabular}

+ , Positive; - , negative; $X$, weak positive; $P$, peptonization; N, no change; F, fermentative.

* Results of the Hugh \& Leifson test indicated fermentation of glucose by all cultures. Parallel results were obtained by Lysenko's iodoacetate method with cultures $\mathrm{S} 1$ to $\mathrm{S} 6$, but alkali production by cultures $\mathrm{A} 1$ to $\mathrm{A} 4$, obscured the reaction.

At $24 \mathrm{hr}$. the serum agar colonies of all strains were punctiform, low convex, undulate, smooth, butyrous, amorphous and translucent. As cultures aged the colonies flattened, enlarged to 1-3 mm. and often became slightly friable in consistency. Fairly rapid degeneration was indicated by decrease in phase density of the organisms in $48 \mathrm{hr}$. colonies. Colonies of strains A1 to A4 showed a tendency to spread.

\section{Metabolism and nutrition}

Anaerobic growth. No growth occurred when plates were incubated in a McIntosh \& Fildes jar, but cultures S5 and S6 produced growth when the pyrogallol method of obtaining anaerobiosis was used. 
Growth temperature. Only the cultures incubated at $37^{\circ}$ produced growth.

$\mathrm{pH}$ value for growth. Cultures grew at $\mathrm{pH} 7$ to 9 .

Utilization of citrate as sole carbon source. No culture grew on Simmons citrate medium.

Growth requirements. Growth on nutrient agar and PYE agar was poor as compared with growth on serum agar. Cultures $S 1$ to $S 6$ produced better growth on nutrient agar than on PYE agar; cultures A1 to A4 showed the reverse effect.

Fermentation of carbohydrates and other biochemical tests

The results are summarized in Tables $\mathbf{1}$ and 2.

\section{DISCUSSION}

Work on Simonsiella and Alysiella spp. has been published by several authors but, to my knowledge, none since 1924. Pure cultures were apparently not studied since isolation of the organisms was not successful and the investigations consisted mainly of morphological studies of stained preparations. The morphological characteristics and habitat of cultures $S 1$ to $S 6$ leave no doubt that they belong to the genus Simonsiella Schmid, 1922. The width of the filament admits them to the species $S$. crassa Schmid, 1922. An insufficient number of strains has been studied as yet to venture an opinion on the justification for the retention of more than one species on the basis of cell width. It has, however, been observed that the width of the isolated cells tends to decrease with long serial subcultivation. Cultures A1 to A4 are so similar in morphology to the published illustration of $S$. filiformis Schmid, 1922, that there can be little doubt of their identity. The question is whether they should be classified in the genus Simonsiella Schmid, 1922 or in the genus Alysiella Langeron, 1923.

Grassé (1924) reported the presence of spores in Alysiella which he considered to be endosporous trichobacteria having affinities with Arthromitus. Endospores were not seen in any of 10 cultures examined here. Langeron and Simons did not observe spores.

Fellinger (1924) was the only author to report motility of Simonsiella. She observed slow gliding motility in a hanging-drop preparation of saliva but was unable to demonstrate organs of motility. She suggested that unilateral contraction of the segmented structure might produce this movement. Fellinger (1924) and Dannenberg (1924) reported both genera as Gram-negative.

In Bergey's Manual (1948) Peshkoff placed the Simonsiella species described by Simons (1922) in the genus Caryophanon. They were re-instated in the genus Simonsiella by Breed (Bergey's Manual, 1957).

In my opinion the described morphological and biochemical differences between strains $\mathrm{S} 1$ to $\mathrm{S} 6$ and strains $\mathrm{A} 1$ to $\mathrm{A} 4$ are sufficiently great to recognize the genus Alysiella Langeron, 1923, with Alysiella filiformis as the type species. Strain S6 (for Simonsiella crassa) and strain Al (for Alysiella filiformis) have been lodged with the National Collection of Type Cultures, London, and are proposed as neotype cultures. They have been assigned the accession numbers NCTC 10283 and NCTC 10282 respectively.

Simonsiella was classified as a member of the family Caryophanaceae in the order Caryophanales, arranged by Peshkoff in 1940 and revised by Breed in 1955, and 
appeared as such in Bergey's Manual (1957). However, the present investigation of Simonsiella and Alysiella has revealed certain features that exclude them from the Caryophanales, namely their peculiar flat form and their gliding motility. This latter character, combined with multicellularity, associates them more closely with the Beggiatoales. Pending the possible erection of a new order it is recommended that the two genera Simonsiella and Alysiella be reclassified into the order Beggiatoales as members of the family Simonsiellaceae fam.nov. of which the genus Simonsiella Schmid, 1922, is the type genus. The descriptions of the new family and the included genera are as follows:

Simonsiellaceae fam.nov. Multicellular organisms, strongly compressed in ribbonlike filaments. Gliding motility.

There are two genera, Simonsiella Schmid and Alysiella Langeron.

Simonsiella Schmid, 1922. Multicellular organisms, strongly compressed in ribbonlike filaments. Filaments divide into hormogonia-like units in which the individual cells are closely apposed and the terminal cells are rounded. Motile with gliding motility.

Alysiella Langeron, 1923. Multicellular organisms, strongly compressed in ribbonlike filaments. Organisms appear to occur in pairs in filaments which tend to break into groups of four or more cells in which the terminal cells are not rounded. Motile with gliding motility.

The amended descriptions of Simonsiella crassa Schmid and Alysiella filiformis (Schmid) Langeron are as follows:

\section{Simonsiella crassa Schmid, 1922, emendavit}

Multicellular, unbranched, non-sporing, ribbon-like filaments 3-4 $\mu$ wide and 1-1.5 $\mu$ thick consisting of closely apposed cells $0 \cdot 6 \mu$ long with the free faces of the terminal cells rounded. The filaments appear to divide by constriction into hormogonia-like units about $4.5 \mu$ long which may remain attached for some time. Filaments may attain a length of $50 \mu$ or more. Phase dense areas may occur centrally in the intercalary cells and as apical thickenings in the terminal cells. The filaments exhibit gliding motility when the broad face is presented to the solid medium but are immotile and show a pronounced tendency to curl when on their edges. Gram-negative, basophilic.

Agar colonies. After 3-4 days, low convex, 1-3 mm. in diameter, smooth, undulate, translucent. Pigment and odour absent. Broth: granular and turbid giving a moderate whitish sediment. Aesculin: no hydrolysis. Gelatin: liquefied. Casein: hydrolysed. Litmus milk: peptonized. Starch: no hydrolysis. Sodium hippurate: no hydrolysis. Inspissated serum: liquefied. Blood agar: $\beta$-haemolysis. Methylene blue not reduced. Nitrate may be reduced to nitrite. Catalase-positive. Ureasenegative. Indole not produced. Methyl red test negative. Voges-Proskauer test negative. Hydrogen sulphide produced. No growth on Simmon's citrate medium. Carbohydrates are fermented (not oxidized); acid but no gas produced from glucose, fructose, ribose, sucrose, maltose, trehalose, inulin; and variable acid production from arabinose and mannitol, on agar or in shallow liquid media. Acid not produced from rhamnose, sorbose, xylose, galactose, mannose, lactose, melibiose, cellobiose, raffinose, melezitose, glycerol, erythritol, sorbitol, dulcitol, inositol or salicin.

Aerobic. Optimum temperature $37^{\circ}$. Source: isolated from sheep saliva. 
Alysiella filiformis (Schmid, 1922) Langeron, 1923, emendavit

Multicellular, unbranched, non-sporing ribbon-like filaments whose cells appear to occur in pairs with a relatively weak linkage between each pair or group of 4 cells. The filaments are of uniform width throughout and the terminal cells are similar to every other cell of the filament in being flat or slightly biconcave. Each cell is 2-3 $\mu$ wide, about $0 \cdot 6 \mu$ long and $0 \cdot 5-1 \mu$ thick. Phase-dense areas may be present in the cells and often occur along one side of the filament. Length of filaments is extremely variable. Gliding motility is exhibited on solid media. Gram-negative, basophilic.

Agar colonies: after 3-4 days, low convex, 1-1.5 mm. in diameter, smooth, undulate, translucent and often with a narrow fringe of gliding filaments and slime trails. Pigment and odour absent. Broth: granular and turbid giving a moderate whitish sediment. Aesculin: no hydrolysis. Gelatin: liquefaction slight or absent. Casein: no hydrolysis. Litmus milk: unchanged. Starch: no hydrolysis. Sodium hippurate: no hydrolysis. Inspissated serum: no liquefaction. Blood agar: $\beta$-haemolysis. Methylene blue not reduced. Nitrate not reduced to nitrite. Catalasepositive. Urease-negative. Indole not produced. Methyl red test negative. VogesProskauer test negative. Hydrogen sulphide may be produced. No growth on Simmon's citrate medium. Carbohydrates are fermented (not oxidized); acid but no gas produced from glucose, fructose, sucrose, maltose and trehalose; variable acid production from ribose and inulin, on agar or in shallow liquid media. Acid not produced from arabinose, rhamnose, sorbose, xylose, galactose, mannose, lactose, melibiose, cellobiose, raffinose, melezitose, glycerol, erythritol, mannitol, sorbitol, dulcitol, inositol, or salicin.

Aerobic. Optimum temperature $37^{\circ}$. Source: isolated from sheep saliva.

I wish to express my thanks to Professor V. B. D. Skerman for his interest and encouragement throughout the work and in the preparation of this paper. Grateful acknowledgement is made to Professor R. E. Buchanan for his advice regarding the validity of the genus Alysiella and for other recommendations.

\section{REFERENCES}

Ayers, S. H. \& RUPP, P. (1922). Differentiation of hemolytic streptococci from human and bovine sources by the hydrolysis of sodium hippurate. J. infect. Dis. 30, 389.

Bergey's Manual of Determinative Bacteriology (1948). 6th ed. Ed. by R. S. Breed, E. G. D. Murray \& A. P. Hitchens. Baltimore: Williams and Wilkins.

Bergey's Manual of Determinative Bacteriology (1957). 7th ed. Ed. by R. S. Breed, E. G. D. Murray \& N. R. Smith. Baltimore: Williams and Wilkins.

Dannenberg, L. (1924). Zur Kenntnis der Schleimhautbakterien und Oscillarien des Geflugels. Arch. Wiss. prakt. Tierheilk. 51, 358.

Fellinger, B. (1924). Untersuchungen über die Mundoscillarien des Menschen. $Z \mathbf{Z b l}$. Bakt. (1 Abt. Orig.), 91, 398.

Grassé, P. P. (1924). Notes Protistologiques. I. La sporulation des Oscillospiracées. II. Le genre Alysiella Langeron 1923. Arch. Zool. exp. Gen. 62, 25.

Hugh, R. \& Leifson, E. (1953). The taxonomic significance of fermentative versus oxidative metabolism of carbohydrates by various Gram negative bacteria. J. Bact. 66, 24.

Kauffmann, F. (1954). Enterobacteriaceae. 2nd ed. Copenhagen: Ejnar Munksgaard.

LANGERon, M. (1923). Les Oscillariées parasites du tube digestif de l'homme et des animaux. Ann. Parasit. hum. comp. 1, 113. 
LEIfson, E. (1951). Staining, shape, and arrangement of bacterial flagella. J. Bact. 62, 377. LeIfson, E. (1958). Timing of the Leifson flagella stain. Stain Tech. 33, 249.

Lysenko, O. (1961). Pseudomonas-An attempt at a general classification. J. gen. Microbiol. 25, 379.

MüllLe, R. (1911). Zur Stellung der Krankheitserreger im Natursystem. Münch. med. Wschr. No. 42, 2247.

Srmons, H. (1922). Saprophytische Oscillarien des Menschen und der Tiere. Zbl. Bakt. (1 Abt. Orig.), 88, 501.

Skerman, V. B. D. (1959). A Guide to the Identification of the Genera of Bacteria. Baltimore: Williams and Wilkins.

SNeath, P. H. A. (1956). Cultural and biochemical characteristics of the genus Chromobacterium. J. gen. Microbiol. 15, 70.

\section{EXPLANATION OF PLATE 1}

Young cultures on serum agar examined by phase contrast microscopy.

Fig. 1. Simonsiella crassa. Note the phase dense areas present centrally $(a)$ within the cells and as apical thickenings $(b)$ in terminal cells.

Fig. 2. Microcolony of Simonsiella crassa showing filaments coiled and on their edges.

Fig. 3. Microcolony of Simonsiella crassa showing commencement of migration of filaments.

Fig. 4. Positions of gliding filaments of Simonsiella crassa at intervals of $10 \mathrm{~min}$. ((i)-(iii)). Note $(a)$ and $(b)$ as in Fig. 1.

Fig. 5. Microcolony of Alysiella filiformis showing very long filaments. Note phase dense areas $(a)$ and lateral view $(b)$ of cells.

Fig. 6. Microcolony of Alysiella filiformis showing very short filaments. Note $(a)$ and $(b)$ as in Fig. 5. 

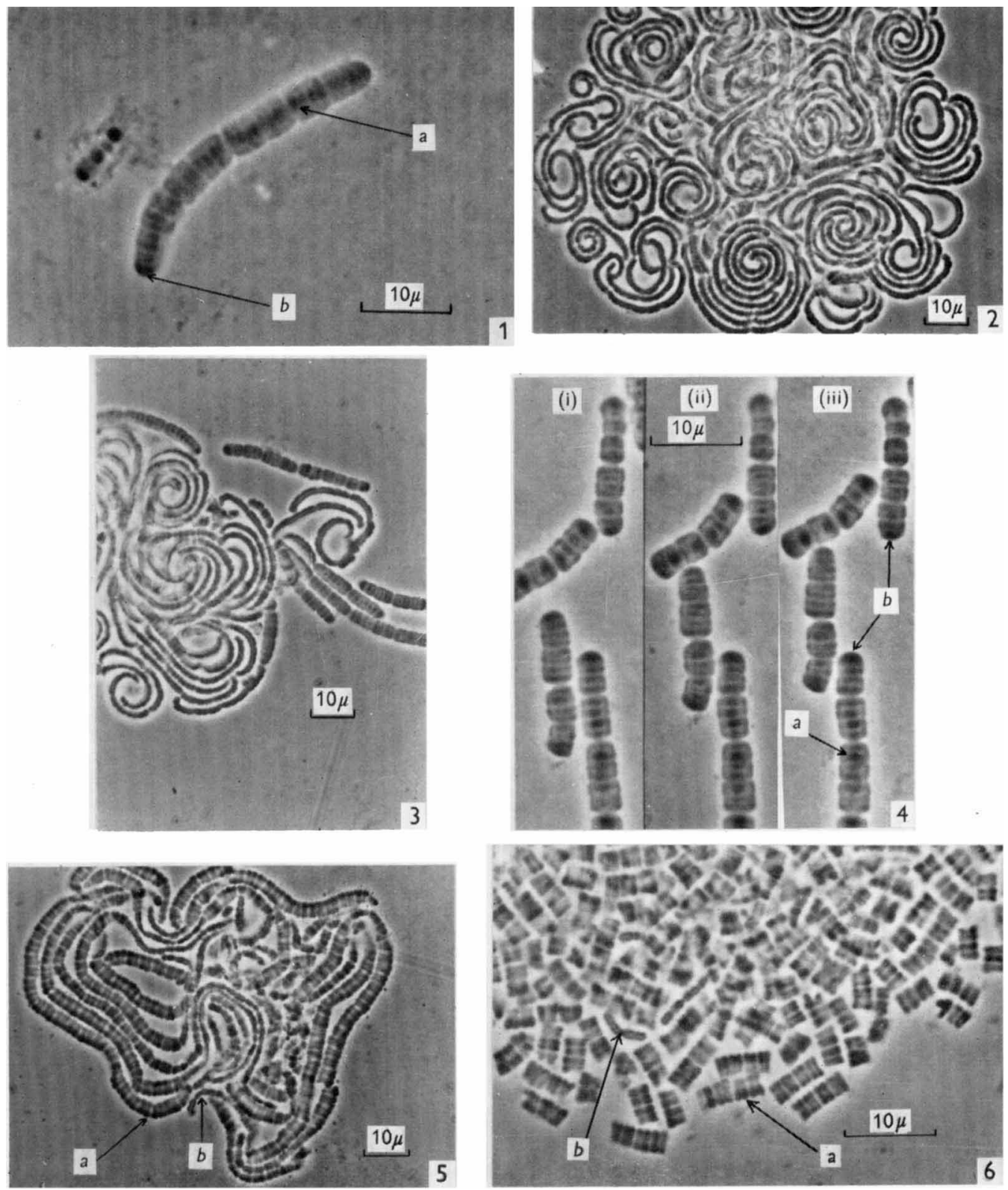